\title{
Dosage Effects of BDNF Val66Met Polymorphism on Cortical Surface Area and Functional Connectivity
}

\author{
Chao Wang, ${ }^{1 *}$ Yuanchao Zhang, ${ }^{1 *}$ Bing Liu, ${ }^{2,3 *}$ Haixia Long, ${ }^{2,3}$ Chunshui Yu, ${ }^{4}$ and Tianzi Jiang ${ }^{1,2,3,5}$ \\ ${ }^{1}$ Key Laboratory for NeuroInformation of Ministry of Education, School of Life Science and Technology, University of Electronic Science and Technology of \\ China, Chengdu 610054, China, ${ }^{2}$ Brainnetome Center and ${ }^{3}$ National Laboratory of Pattern Recognition, Institute of Automation, Chinese Academy of \\ Sciences, Beijing 100190, China, ${ }^{4}$ Department of Radiology, Tianjin Medical University General Hospital, Tianjin 300052, China, and ${ }^{5}$ Queensland Brain \\ Institute, University of Queensland, Brisbane, QLD 4072, Australia
}

The single nucleotide polymorphism (SNP) that leads to a valine-to-methionine substitution at codon 66 (Val66Met) in BDNF is correlated with differences in cognitive and memory functions, as well as with several neurological and psychiatric disorders. MRI studies have already shown that this genetic variant contributes to changes in cortical thickness and volume, but whether the Val66Met polymorphism affects the cortical surface area of healthy subjects remains unclear. Here, we used multimodal MRI to study whether this polymorphism would affect the cortical morphology and resting-state functional connectivity of a large sample of healthy Han Chinese human subjects. An SNP-wise general linear model analysis revealed a "dosage effect" of the Met allele, specifically a stepwise increase in cortical surface area of the right anterior insular cortex with increasing numbers of the Met allele. Moreover, we found enhanced functional connectivity between the anterior insular and the dorsolateral prefrontal cortices that was linked with the dosage of the Met allele. In conclusion, these data demonstrated a "dosage effect" of BDNF Val66Met on normal cortical structure and function, suggesting a new path for exploring the mechanisms underlying the effects of genotype on cognition.

Key words: anterior insula; brain-derived neurotrophic factor (BDNF); functional connectivity; surface area

\section{Introduction}

Brain-derived neurotrophic factor (BDNF) is strongly expressed in the CNS, including the hippocampus (Conner et al., 1997) and cerebral cortex (Hofer et al., 1990) and plays an essential role in regulating neural development, synaptic plasticity, and dendritic growth neurogenesis (Poo, 2001; Binder and Scharfman, 2004). A functional polymorphism in the BDNF gene, specifically, a valine-to-methionine substitution at codon 66 (Val66Met) in the $5^{\prime}$ proregion, has been reported as affecting intracellular processing and activity-dependent BDNF secretion (Egan et al., 2003; Chen et al., 2004). Impaired memory performance (Egan et al., 2003; Hariri et al., 2003) and reduced cognitive performance (Guerini et al., 2009; Schofield et al., 2009) have been associated with the Met allele. It also has been related to increased susceptibility to a number of neuropsychiatric disorders, including

Received Aug. 14, 2013; revised Jan. 4, 2014; accepted Jan. 10, 2014.

Author contributions: C.W., Y.Z., B.L., H.L., C.Y., and T.J. designed research; C.W. and B.L. performed research; C.W. contributed unpublished reagents/analytic tools; C.W., Y.Z., and H.L. analyzed data; C.W., Y.Z., B.L., and T.J. wrote the paper.

This work was supported in part by the National Key Basic Research and Development Program (973) (Grant 2011(B707800), the Strategic Priority Research Program of the Chinese Academy of Sciences (Grant XDB02030300), the Natural Science Foundation of China (Grants 91132301, 91232718, and 81101000), and the Beijing Nova Program (Grant 2010B06). We thank Drs. Rhoda E. and Edmund F. Perozzi for English and content editing assistance and discussions.

The authors declare no competing financial interests.

${ }^{*}$ C.W., Y.Z., and B.L. contributed equally to this work and should be considered co-first authors.

Correspondence should be addressed to Dr. Tianzi Jiang, Brainnetome Center, Institute of Automation, Chinese Academy of Sciences, Beijing 100190, China. E-mail: jiangtz@nlpr.ia.ac.cn.

DOI:10.1523/JNEUROSCI.3501-13.2014

Copyright $\odot 2014$ the authors $\quad 0270-6474 / 14 / 342645-07 \$ 15.00 / 0$ schizophrenia (Eisenberg et al., 2013) and Alzheimer's disease (Voineskos et al., 2011). In addition, diffusion tensor imaging studies have found the association between this variant and white matter microstructure (Carballedo et al., 2012; Tost et al., 2013).

Many previous studies have shown that the Met allele contributes to reduced cortical volume in the hippocampus (Pezawas et al., 2004; Frodl et al., 2007), prefrontal cortex (Pezawas et al., 2004), and temporal and occipital lobar regions (Ho et al., 2006), independent of clinical diagnosis. However, some studies were not able to detect any genetic impact on cortical volume (Jessen et al., 2009; Koolschijn et al., 2010), which might be attributed to the differences in sample size and methodological approaches. It is also noteworthy that cortical volume comprises both surface area and cortical thickness, only assessing cortical volume may obscure individual differences. Previous studies suggested that these two components of cortical volume are genetically and phenotypically independent (Panizzon et al., 2009; Eyler et al., 2011). Hence, separating the analyses of these independent factors may help clarify the relationship between genetics and the basic structural elements of the cerebral cortex. To date, the studies have just focused on genetic effects on cortical thickness, which displayed BDNF-associated changes in the temporal gyrus and prefrontal cortex (Lotfipour et al., 2009; Lyoo et al., 2011; Voineskos et al., 2011), but little research has been performed on BDNFassociated effects on surface area. The cortical surface area is a highly heritable trait (Eyler et al., 2011) and has been shown to be correlated with cognitive performance (Koscik et al., 2009) and Alzheimer's disease (Dickerson et al., 2009). The increased size of the human cortex compared with animals may be driven primar- 
Table 1. Subject demographics for different genotype groups

\begin{tabular}{|c|c|c|c|c|c|c|c|}
\hline & \multicolumn{2}{|c|}{$\begin{array}{l}\text { Met/Met } \\
(N=57)\end{array}$} & \multicolumn{2}{|c|}{$\begin{array}{l}\mathrm{Val} / \text { Met } \\
(N=156)\end{array}$} & \multicolumn{2}{|c|}{$\begin{array}{l}\mathrm{Val} / \mathrm{Val} \\
(N=95)\end{array}$} & \multirow[b]{2}{*}{$p$ value } \\
\hline & Mean & SD & Mean & SD & Mean & SD & \\
\hline Male/female & $28 / 29$ & & $71 / 85$ & & $50 / 45$ & & $0.545^{a}$ \\
\hline Age & 22.35 & 2.50 & 22.67 & 2.41 & 22.97 & 2.70 & $0.333^{b}$ \\
\hline Education & 15.11 & 3.18 & 15.48 & 2.71 & 15.86 & 2.04 & $0.256^{b}$ \\
\hline IQ & 114.88 & 11.77 & 116.60 & 8.41 & 115.75 & 10.18 & $0.531^{b}$ \\
\hline \multicolumn{8}{|c|}{ Working memory } \\
\hline 2-back_CR & 89.13 & 5.21 & 88.48 & 6.02 & 87.86 & 8.51 & $0.567^{b}$ \\
\hline 3-back_CR & 82.30 & 4.49 & 81.18 & 6.89 & 81.26 & 9.62 & $0.689^{b}$ \\
\hline \multicolumn{8}{|l|}{ WCST } \\
\hline CC & 4.98 & 1.71 & 4.99 & 1.74 & 4.96 & 1.74 & $0.997^{b}$ \\
\hline $\mathrm{RC}$ & 70.96 & 13.33 & 70.60 & 11.17 & 70.24 & 11.74 & $0.973^{b}$ \\
\hline PRC & 68.97 & 15.88 & 68.73 & 14.10 & 69.17 & 15.12 & $0.909^{b}$ \\
\hline
\end{tabular}

CR, Correction rate; WCST, Wisconsin Card Sorting Test; CC, categories completed; RC, total correct responses; PRC, percent correct responses.

${ }^{a} p$ value (Pearson $\chi^{2}$ test).

${ }^{b} p$ value (ANOVA).

ily by changes in the surface area (Rakic, 2009). Therefore, cortical surface area may be a promising endophenotype for understanding human brain development.

To elucidate the effects of Val66Met on cortical development and morphology, we used cortical thickness and surface area measures to analyze the "dosage effect"s of the Val66Met polymorphism. Furthermore, because of the regulating effect of BDNF on synaptic plasticity, we speculated that this polymorphism would mediate the functional connectivity between areas that vary with BDNF genotype and the rest of the brain.

\section{Materials and Methods}

Subjects. We recruited 323 healthy Chinese subjects (157 males and 166 females, mean age 22.7 years, range $18-31$ years) (see Table 1 for additional demographic details) and provided written informed consent in accordance with the local Medical Research Ethics Committee of Tianjin Medical University. All subjects were right-handed and Han Chinese in origin. The exclusion criteria were the same as those reported in our previous studies that used this same database (Li et al., 2013). We carefully asked subjects to ensure that had no personal or family history of neurological or psychiatric disease, head injury, psychiatric treatment, drug or alcohol abuse, hypothyroidism, or other mental diseases and no contraindications to MRI screening. We used many neuropsychological tests, including the Chinese Revised Wechsler Adult Intelligence Scale (Gong, 1982), the Wisconsin Card Sorting Test (Heaton, 1999), and $n$-back working memory tasks (Owen et al., 2005) to assess memory and executive functions. Fifteen subjects were excluded from the structural MRI analysis, and 43 subjects were discarded in the fMRI analysis due to missing genotype data and poor imaging quality.

DNA extraction and BDNF Val66Met genotyping. We extracted the genomic DNA from whole blood using EZgene Blood gDNA Miniprep Kit (Biomiga) and then genotyped the BDNF Val66Met in all subjects using the PCR and ligation detection reaction (LDR) method (Thomas et al., 2004; Yi et al., 2009). The PCR primer sequences of $b d n f$ were designed as follows: forward: 5' ACAAGGTGGCTTGGCCTAC 3', reverse $5^{\prime}$ AGAAGAGGAGGCTCCAAAGG $3^{\prime}$. The three probes used in the LDR reactions included one common probe (rs6265_modify: P-GTGTT CGAAAGTGTCAGCCAATGATTTTTTTTTTTTTTTTTTTTT-FAM) and two discriminating probes (rs6265_A: TTTTTTTTTTTTTTTTTTTT CCTCATCCAACAGCTCTTCTATCAT and rs6265_G: TTTTTTTTTTTT TTTTTTTTTTCCTCATCCAACAGCTCTTCTATCAC). Because of missing BDNF genotype data, 14 subjects were excluded from the following analysis, leaving 309 subjects in total.

MRI acquisition. T1 images were collected from all subjects using a single 3T GE scanner (SIGNAHDX3.0 T scanner; GE Healthcare) equipped with a standard head coil and a high-resolution T1-weighted brain volume (BRAVO) 3D MRI sequence $(\mathrm{TR}=8.1 \mathrm{~ms}, \mathrm{TE}=3.1 \mathrm{~ms}$, 176 sagittal slices, flip angle $=13^{\circ}$, voxel size $=1 \mathrm{~mm} \times 1 \mathrm{~mm} \times 1 \mathrm{~mm}$ ) to obtain $3 \mathrm{D}$ datasets across the entire cranium. For the resting-state scan, a single-shot, gradient-echo, echo-planar-imaging sequence sensitive to blood oxygen level-dependent contrast $(\mathrm{TR}=2000 \mathrm{~ms}, \mathrm{TE}=30$ $\mathrm{ms}$, no gap, voxel size $=3.75 \mathrm{~mm} \times 3.75 \mathrm{~mm} \times 4.0 \mathrm{~mm}$, FOV $=240 \times$ $240 \mathrm{~mm}^{2}$, matrix $=64 \times 64$, flip angle $=90^{\circ}, 40$ slices, 180 volumes $)$ was used to acquire fMRI data. Before the resting-state fMRI examination, all subjects were emphasized to relax, lie still with their eyes closed, and not to fall asleep. Meanwhile, we further checked whether they had fallen asleep or not during and after the scanning.

Structural MRI analysis. Each scan was processed using the FreeSurfer package (which is freely available to the research community at http:// surfer.nmr.mgh.harvard.edu/) to obtain the cortical thickness and local surface area measurements. In brief, the stripped, intensity-corrected, subdivided volume was segmented to classify the white matter and to approximate the gray-white matter boundary for each cortical hemisphere. From this, a topologically correct, gray-white matter boundary surface triangulation was generated (Dale et al., 1999; Fischl et al., 2001). Subsequently, a pial surface was generated using a deformable surface algorithm. After obtaining the pial surface, we obtained a cortical thickness map by using the T-average algorithm (Fischl and Dale, 2000; Han et al., 2006). Vertexwise estimates of the surface area were calculated by assigning one-third of the area of each triangle to each of its vertices. For comparison, all of the individual reconstructed cortical surfaces were aligned to an average template by using a surface-based registration algorithm. The thickness and area maps were resampled and smoothed with a heat kernel of $20 \mathrm{~mm}$ width. Before statistical analysis, the results for each subject were visually checked for gross topological differences, and one subject with major differences was excluded. In the end, 308 subjects were included in the structural MRI analysis $(\mathrm{Val} / \mathrm{Val}=95$; $\mathrm{Val} / \mathrm{Met}=156$; Met $/ \mathrm{Met}=57$ ).

$f M R I$ analysis. All the raw fMRI data were inspected by two experienced radiologists who knew nothing about the genotype information. Fourteen subjects were excluded because of bad imaging quality, such as apparent signal loss and interslice motion artifacts. Imaging data were preprocessed using DPARSFA (Data Processing Assistant for RestingState fMRI Advanced Edition, http://www.restfmri.net/forum/DPARSF). The first 10 volumes of each scan were discarded to allow for magnetization equilibrium. Subsequent preprocessing included slice timing, head motion correction, spatially normalizing to the MNI template, resampling to $2 \times 2 \times 2 \mathrm{~mm}^{3}$, smoothing with a $4 \mathrm{~mm}$ Gaussian kernel to decrease spatial noise, temporal bandpass filtering, and regressing out nuisance signals including head motion parameters and white matter, CSF, and global signals. A further 14 participants who exhibited a maximum displacement in any of the cardinal directions $(x, y, z)$ of $>2 \mathrm{~mm}$, or a maximum spin $(x, y, z)$ of $>2^{\circ}$ were excluded. In the end, 280 subjects were included in the functional connectivity analysis $(\mathrm{Val} / \mathrm{Val}=89$; $\mathrm{Val} / \mathrm{Met}=142$; Met $/ \mathrm{Met}=49$ ).

The region with significant group differences in the cortical surface area analysis was extracted as an ROI. We resampled the ROI mask to $2 \times$ $2 \times 2 \mathrm{~mm}^{3}$ in MNI space and calculated the average time series of the seed ROI for each subject. Then we computed Pearson correlation coefficients between the mean time series of the ROI and those of all the voxels throughout the whole brain and converted the correlation coefficient to $z$ values using Fisher's $r$-to- $z$ transformation to improve normality. Using these values, we generated $z$-functional connectivity maps for each subject. To identify the clusters that showed significant functional connectivity with the ROI, we conducted a one-sample $t$ test on the $z$-functional connectivity maps of each individual to detect whether they were significantly different from zero $(p<0.05$, familywise error [FWE] correction). SNP-wise univariate general linear models (GLMs) were used to compute the effects of the BDNF genotype on the functional connectivity within the gray matter mask, with age and sex as covariates. All the statistical steps were completed using statistical parametric mapping (SPM8, http://www.fil.ion.ucl.ac.uk/spm).

Statistical analysis. A $\chi^{2}$ test was used to see whether the allele frequencies of BDNF Val66Met fell within the Hardy-Weinberg equilibrium. Vertex-by-vertex analyses of cortical thickness and surface area were 
A
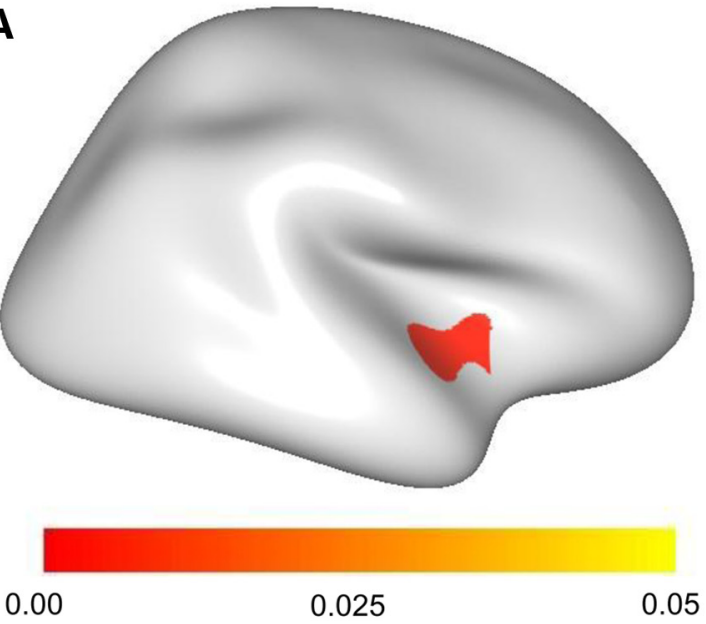

B

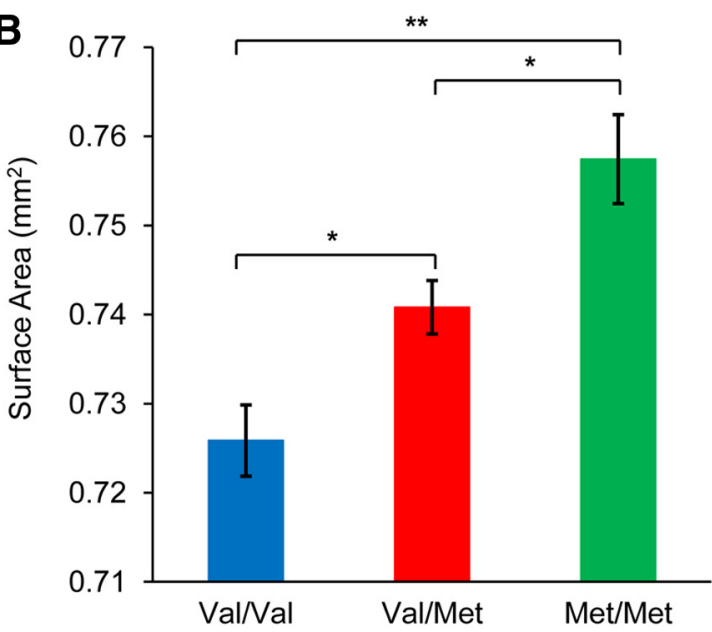

Figure 1. Association of BDNF Val66Met with cortical surface area in all participants. $\boldsymbol{A}$, The map shows the region with a significant linear increase in the cortical surface area in which Val/Val $<$ $\mathrm{Val} /$ Met $<$ Met/Met. The color bar indicates $p$ values. The corrected $p$ values were obtained using random field theory. $\boldsymbol{B}$, Mean $\pm \mathrm{SEM}$ surface area of the survived regions after correction in the BDNF genotype groups. ${ }^{*} p<0.01$ (two-sample $t$ test). ${ }^{* *} p<0.001$ (two-sample $t$ test).

performed using the SurfStat package (http://www.math.mcgill.ca/ keith/surfstat/). To test dose-dependent genotype effects of the BDNF gene, we modeled Met allele as additive. Specifically, SNP-wise GLMs were fitted with morphological phenotypes as the dependent variables and genotype as the independent variable. And the genotype group was treated as a linear ordered factor (i.e., $\mathrm{Val} / \mathrm{Val}=0, \mathrm{Val} / \mathrm{Met}=1$, Met/ Met $=2$ ) in a GLM. Subsequently, a corrected clusterwise $p$ value was obtained using random field theory (Hayasaka et al., 2004). The level of significance for the vertices was set at a conservative, surface-wide $p<$ 0.05 after a multiple comparisons correction. In the same way, we extracted the significant region in the SNP-wise GLMs based on functional connectivity and averaged the $z$-scores in the region for each subject. We performed the cluster-level FWE correction throughout the whole brain, and a two-stage procedure was followed: (1) thresholding result image voxelwise at a certain uncorrected $p$ value (here $p<0.001$ was set); and (2) applying cluster-level inference to keep only those clusters that are big enough to ensure an overall (familywise) $p<0.05$. We then performed an ANOVA and two-sample $t$ tests with a $p$ value of 0.05 as the threshold for statistical significance.

\section{Results}

\section{Demographic and genetic characteristics}

The frequencies of the two BDNF alleles were 0.562 for $\mathrm{Val}$ and 0.438 for Met. The genotype frequencies $(\mathrm{Val} / \mathrm{Val}=0.307, \mathrm{Val} /$ Met $=0.508$, Met $/$ Met $=0.185)$ were within the Hardy-Weinberg equilibrium $\left(\chi^{2}=0.312, p=0.856\right)$. No genotypic differences were found for demographic (age, sex, education) and cognitive variables (IQ, working memory, and executive function) (all $p>0.05$; Table 1).

\section{BDNF Val66Met and cortical morphology}

The surface area analysis showed significantly positive correlations between the dosage of the Met allele and the surface area in the right anterior insular cortex (including a few parts of the superior temporal gyrus) ( $p<0.05$, the cluster-based random field theory correction), whereas no significant correlation was observed between cortical thickness and the dosage of the Met allele, no cluster survived even under the threshold of an uncorrected $p<0.001$. Significant intergroup differences in the mean surface area of all the vertices in this cluster were also observed $\left(F_{(2,307)}=11.53, p<0.001\right)$ (Fig. 1).

\section{BDNF Val66Met and functional connectivity}

We further investigated the functional connectivity between the anterior insular cortex and the whole brain and found that the anterior insular cortex was significantly positive correlated with the dorsolateral prefrontal cortex (DLPFC). We also found a positive correlation between the dose of the Met allele and the functional connectivity between the dorsolateral prefrontal cortex and the right anterior insular cortex $(\mathrm{Val} / \mathrm{Val}<\mathrm{Val} / \mathrm{Met}<\mathrm{Met} /$ Met) (Fig. 2; Table 2). Similarly, we found that the mean $Z$ scores significantly increased with the number of Met alleles $\left(F_{(2,279)}=\right.$ $10.51, p<0.001)$.

\section{Discussion}

This study demonstrated that a functional variation at the Val66Met locus in the 5' prodomain of BDNF impacted cortical surface area and resting-state functional connectivity in a large sample of healthy Chinese subjects. Specifically, the Met allele was associated with surface expansion in the right anterior insular cortex, but we did not find significant effects on cortical thickness. We also observed a trend toward increased functional connectivity between the DLPFC and the anterior insular cortex based on resting-state functional data. Therefore, we have identified obvious, robust "dosage effects" in both the cortical morphology and the resting-state functional network. These effects are presumably caused by abnormal intracellular packaging and regulation of the secretion of BDNF in the presence of Met (Egan et al., 2003; Chen et al., 2004). These abnormalities cause changes in the BDNF activity-dependent processes of human brain development and cortical plasticity.

We found that Met homozygotes had the significantly largest surface area in the anterior insular cortex. Previous studies have reported significant differences between the genotypic groups in the cortical volume or gray matter volume of the medial temporal lobe (Pezawas et al., 2004; Frodl et al., 2007), which does not contradict our results given that a new endophenotype (surface area) was adopted to assess the allelic effect of the risk Met allele. Such methodological difference may account for the inconsistency. In addition, several researches on neuropsychiatric disorders, such as schizophrenia, has shown increased cortical surface area in the temporal and paralimbic regions of patients and their 


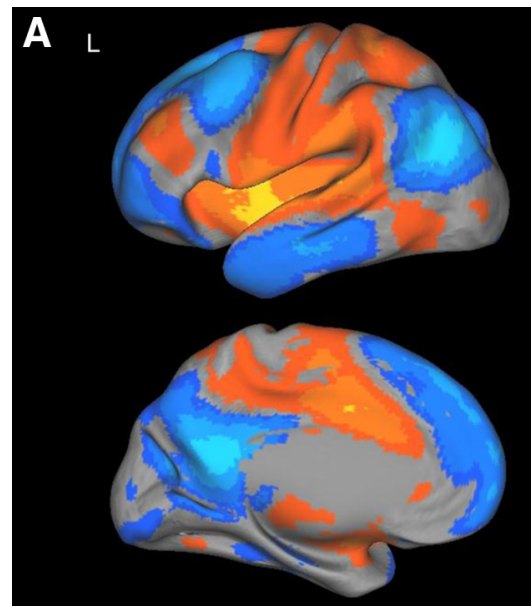

B

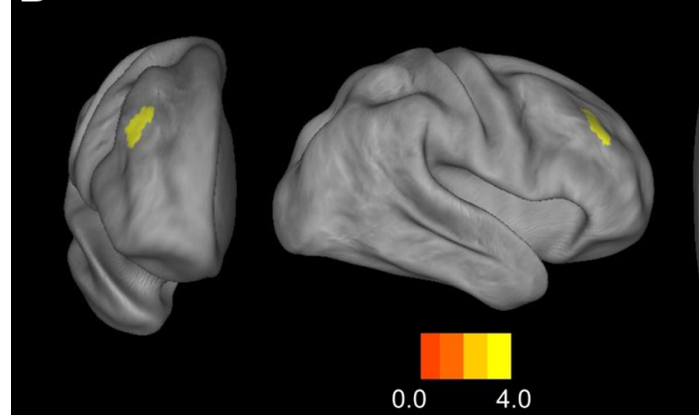

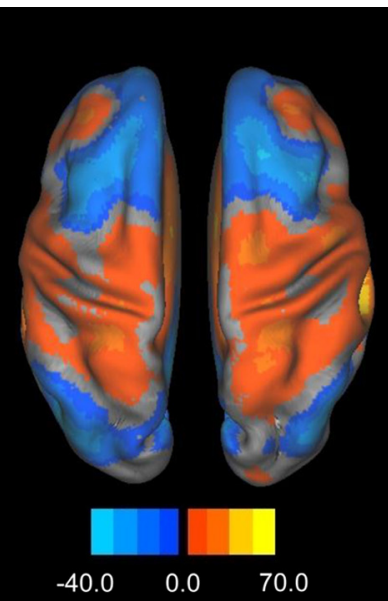

70.0

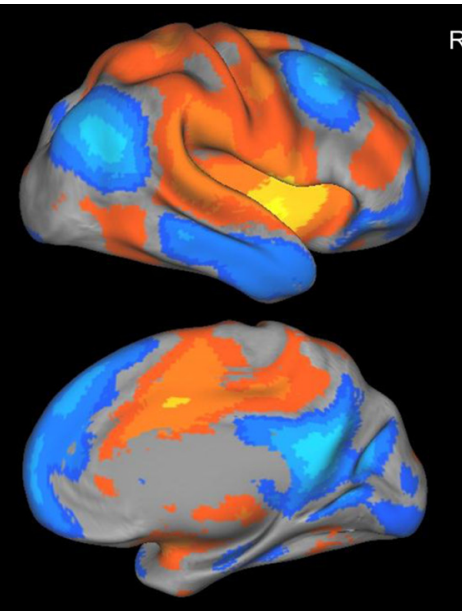

C

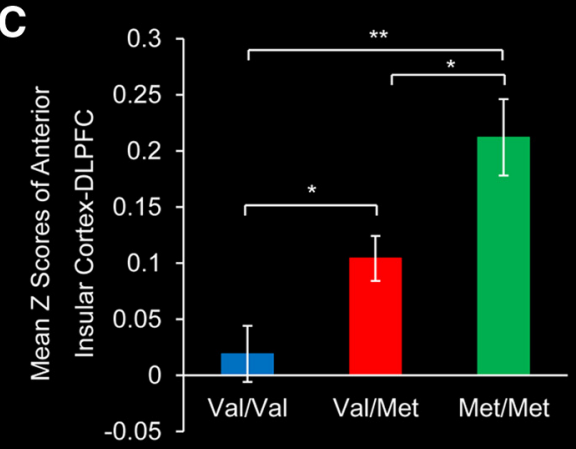

Figure 2. Association of BDNF Val66Met with functional connectivity in resting-state networks. $A$, Resting-state functional connectivity pattern between the significantly associated region of the cortical surface area and the rest of the brain across all subjects (FWE-corrected $p<0.01$ ). Red color represents positive connectivity; and blue represents negative connectivity. L, Left; $\mathrm{R}$, right. $\boldsymbol{B}$, The right DLPFC shows a significant linear increase in coupling with the ROI (Val/Val $<\mathrm{Val} / \mathrm{Met}<\mathrm{Met} / \mathrm{Met}$ ). The color bar indicates T-scores (FWE-corrected at cluster level, $p<0.05)$. C, Mean \pm SEM functional connectivity between the ROI and the DLPFC in Figure 2 across all subjects. ${ }^{*} p<0.01$ (two-sample $t$ test). ${ }^{* *} p<0.001$ (two-sample $t$ test).

Table 2. The right DLPFC shows significantly increased functional connectivity with the survived region in cortical surface area ${ }^{a}$

\begin{tabular}{llllllll}
\hline & & & & \multicolumn{3}{c}{ MNI coordinates } \\
\cline { 5 - 7 } Brain region & Cluster size & $t$ & $z$ & $x$ & $y$ & $z$ \\
\hline Right DLPFC & 183 & 4.16 & 4.09 & 40 & 38 & 34 \\
\hline
\end{tabular}

${ }^{a}$ The brain region in the table was significant at $p<0.05$ (FWE-corrected at cluster level).

healthy relatives (Goghari et al., 2007; Fornito et al., 2008; Chakravarty et al., 2012). Although these results have not been entirely consistent, an increase in surface area may provide some clues to understanding the underlying neurophysiology of the changes found in such diseases. The reason why surface expansion would be important might be explained by one or more of the following. First, increased surface area may indicate exaggerated normal neurodevelopmental processes during brain growth (Fornito et al., 2008). Another possibility is that these effects may reflect more interneurons, larger cells, or less dense cell packing at the cellular level (Goghari et al., 2007). A third possible explanation is that cortical surface area is related to the degree of cortical folding (Jubault et al., 2011). The more tension along an axon or the more shrinkage of white matter fibers, the deeper the sulci and the more extensive the cortical surface area (Van Essen, 1997). So, to some extent, the dose-dependent cortical surface area expansion associated with the Met allele might indirectly mirror changes in the white matter.

Interestingly, in the current study, we found that the BDNF Val66Met variations were associated with cortical surface area, but not with thickness. According to a biological study, cortical surface area and thickness are determined by intermediate progenitor cells and radial progenitor cells, respectively (Pontious et al., 2008). The radial unit hypothesis related the cortical surface area to the number of cellular columns, and the cortical thickness to the number of cells in a column (Rakic, 1988). Furthermore, a recent twin study indicated that the cortical surface area in the adult brain may be determined by genes during both early growth and later development of the brain, including synaptogenesis and dendritic arborization (Eyler et al., 2011). BDNF, as a neurotrophin, plays critical roles in neuronal survival, migration, dendritic arborization, synaptogenesis, and synaptic plasticity (Huang and Reichardt, 2001; Poo, 2001; Binder and Scharfman, 2004). The cortical surface area, which is not only a heritable trait but also genetically distinct from cortical thickness, is an endophenotype worth using (Panizzon et al., 2009). A previous study of a different group of Chinese subjects reported different cortical thinning regions in the Met/Met and the Val/Met when each allele pair was compared separately to the $\mathrm{Val} / \mathrm{Val}$ group (Yang et al., 2012). These findings may suggest that the effects of BDNF Val66Met on cortical thickness are not dosage dependent. Therefore, elucidating the dosage effect of BDNF Val66Met on cortical surface area may yield significant insights.

We also observed a trend toward increased functional connectivity between the anterior insula and the DLPFC that was linked with the dosage of the Met allele. Indeed, the insula is a brain area functionally implicated in high-level cognitive control, performance monitoring, emotion awareness, and automatic and sensory processes (Allen et al., 2008; Craig, 2009). Specifically, the anterior insula is a key node in the salience network that unites 
internal and extra-personal stimuli to decide the next behavior (Seeley et al., 2007) and respond to the degree of cognitive, homeostatic, or emotional salience (Critchley, 2005). The anterior insula also plays a critical role in switching information between the central executive network (CEN) and the default mode network (Sridharan et al., 2008). In particular, the CEN and the salience network both show increases in activation during the performance of cognitive tasks (Greicius et al., 2003; Fox et al., 2006). Also, the prefrontal cortex expresses large amounts of BDNF, and the DLPFC, which impacts cognitive control functions, including learning, memory, attention, inhibition, and abstract reasoning throughout life, is a critical node of the CEN (Weickert et al., 2003; Baquet et al., 2004; Seeley et al., 2007; Sridharan et al., 2008). In addition, Sridharan et al. (2008) argued that, during auditory and visual tasks, the anterior insula responds briefly to the events that are perceived as salient. Menon and Uddin (2010) posited that the anterior insula sends brief control signals to brain areasm such as the DLPFC and ventral medial prefrontal cortex to mediate attention and memory with higher-order cognitive processes. Increased functional connectivity between the anterior insula and the DLPFC could possibly be a compensatory modulation that functions by triggering stronger cognitive control signals via the DLPFC to offset the affected cortical morphology in the anterior insula. We observed no significant effects of BDNF Val66Met on the behavioral measurements of cognition that we used, or correlations between the insular surface area and any of cognitive measure of interest within each group, but this polymorphism clearly caused structural and functional changes in cortical areas. This was most commonly seen in imaging genetics research (Dennis et al., 2010; Liu et al., 2010), given that the structural and functional changes in cortical areas, which are considered to be the endophenotypes, are more incisive and sensitive to the impact of functional genetic polymorphisms than the behavioral measurements of cognition.

One of the limitations in the current study was that no clinical tools were used to screen the participants regarding absence of psychiatric and neurologic disorders. However, we carefully asked volunteers to exclude some with any history of neurologic or psychiatric diseases or substance abuse. Previous psychiatric epidemiological surveys have indicated that the prevalence of any mental disorder was lower in metropolitan China in general (Demyttenaere et al., 2004; Shen et al., 2006), whereas the ratio in our sample should typically be much less than previous studies. Hence, these results should remain credible and thought to be obtained in a healthy population, and this study included a large genetically homogeneous sample to ensure the statistical power. Moreover, recent studies have found that resting state functional connectivity is lower in the eyes closed condition compared with the eyes open condition (Yan et al., 2009; Van Dijk et al., 2010; Patriat et al., 2013). Although there is no agreed criterion, instructing all the subjects with eyes closed during scanning makes the resting-state fMRI data comparable. In addition, although this is an interesting finding that BDNF variants have effects on the surface area of the insular cortex, there is still no direct evidence to support this finding because the influence of BDNF variant on surface area is a complex process. Future studies are warranted to discover the BDNF-related changes of neurons of the insular cortex, which may be helpful to validate our interpretation.

In conclusion, we demonstrated a "dosage effect" of BDNF Val66Met on the cortical surface area and the related resting state functional network in a group of healthy Chinese subjects. The anterior insula and DLPFC are both engaged in cognitive control, and the anterior insula, in particular, plays a critical and causal role in switching signals between the CEN and the default mode network. Therefore, cortical surface area may be a promising endophenotype for exploring the mechanisms underlying the effects of genotype on cognition. From such studies, we might gain a better understanding of the neurophysiological mechanisms of neurological or psychiatric diseases.

\section{References}

Allen JS, Emmorey K, Bruss J, Damasio H (2008) Morphology of the insula in relation to hearing status and sign language experience. J Neurosci 28:11900-11905. CrossRef Medline

Baquet ZC, Gorski JA, Jones KR (2004) Early striatal dendrite deficits followed by neuron loss with advanced age in the absence of anterograde cortical brain-derived neurotrophic factor. J Neurosci 24:4250-4258. CrossRef Medline

Binder DK, Scharfman HE (2004) Brain-derived neurotrophic factor. Growth Factors 22:123-131. CrossRef Medline

Carballedo A, Amico F, Ugwu I, Fagan AJ, Fahey C, Morris D, Meaney JF, Leemans A, Frodl T (2012) Reduced fractional anisotropy in the uncinate fasciculus in patients with major depression carrying the met allele of the Val66Met brain-derived neurotrophic factor genotype. Am J Med Genet 159B:537-548. CrossRef Medline

Chakravarty MM, Felsky D, Tampakeras M, Lerch JP, Mulsant BH, Kennedy JL, Voineskos AN (2012) DISC1 and striatal volume: a potential risk phenotype for mental illness. Front Psychiatry 3:57. CrossRef Medline

Chen ZY, Patel PD, Sant G, Meng CX, Teng KK, Hempstead BL, Lee FS (2004) Variant brain-derived neurotrophic factor (BDNF) (Met66) alters the intracellular trafficking and activity-dependent secretion of wildtype BDNF in neurosecretory cells and cortical neurons. J Neurosci 24: 4401-4411. CrossRef Medline

Conner JM, Lauterborn JC, Yan Q, Gall CM, Varon S (1997) Distribution of brain-derived neurotrophic factor (BDNF) protein and mRNA in the normal adult rat CNS: evidence for anterograde axonal transport. J Neurosci 17:2295-2313. Medline

Craig AD (2009) How do you feel-now? The anterior insula and human awareness. Nat Rev Neurosci 10:59-70. CrossRef Medline

Critchley HD (2005) Neural mechanisms of autonomic, affective, and cognitive integration. J Comp Neurol 493:154-166. CrossRef Medline

Dale AM, Fischl B, Sereno MI (1999) Cortical surface-based analysis. I. Segmentation and surface reconstruction. Neuroimage 9:179-194. CrossRef Medline

Demyttenaere K, Bruffaerts R, Posada-Villa J, Gasquet I, Kovess V, Lepine JP, Angermeyer MC, Bernert S, de Girolamo G, Morosini P, Polidori G, Kikkawa T, Kawakami N, Ono Y, Takeshima T, Uda H, Karam EG, Fayyad JA, Karam AN, Mneimneh ZN, et al. (2004) Prevalence, severity, and unmet need for treatment of mental disorders in the World Health Organization World Mental Health Surveys. JAMA 291:2581-2590. CrossRef Medline

Dennis NA, Need AC, LaBar KS, Waters-Metenier S, Cirulli ET, Kragel J, Goldstein DB, Cabeza R (2010) COMT val108/158 met genotype affects neural but not cognitive processing in healthy individuals. Cereb Cortex 20:672-683. CrossRef Medline

Dickerson BC, Feczko E, Augustinack JC, Pacheco J, Morris JC, Fischl B, Buckner RL (2009) Differential effects of aging and Alzheimer's disease on medial temporal lobe cortical thickness and surface area. Neurobiol Aging 30:432-440. CrossRef Medline

Egan MF, Kojima M, Callicott JH, Goldberg TE, Kolachana BS, Bertolino A, Zaitsev E, Gold B, Goldman D, Dean M, Lu B, Weinberger DR (2003) The BDNF val66met polymorphism affects activity-dependent secretion of BDNF and human memory and hippocampal function. Cell 112:257269. CrossRef Medline

Eisenberg DP, Ianni AM, Wei SM, Kohn PD, Kolachana B, Apud J, Weinberger DR, Berman KF (2013) Brain-derived neurotrophic factor (BDNF) Val(66)Met polymorphism differentially predicts hippocampal function in medication-free patients with schizophrenia. Mol Psychiatry 18:713-720. CrossRef Medline

Eyler LT, Prom-Wormley E, Panizzon MS, Kaup AR, Fennema-Notestine C, Neale MC, Jernigan TL, Fischl B, Franz CE, Lyons MJ, Grant M, Stevens A, Pacheco J, Perry ME, Schmitt JE, Seidman LJ, Thermenos HW, Tsuang MT, Chen CH, Thompson WK, et al. (2011) Genetic and environmental contributions to regional cortical surface area in humans: a magnetic resonance imaging twin study. Cereb Cortex 21:2313-2321. CrossRef Medline

Fischl B, Dale AM (2000) Measuring the thickness of the human cerebral 
cortex from magnetic resonance images. Proc Natl Acad Sci U S A 97: 11050-11055. CrossRef Medline

Fischl B, Liu A, Dale AM (2001) Automated manifold surgery: constructing geometrically accurate and topologically correct models of the human cerebral cortex. IEEE Trans Med Imaging 20:70-80. CrossRef Medline

Fornito A, Yücel M, Wood SJ, Adamson C, Velakoulis D, Saling MM, McGorry PD, Pantelis C (2008) Surface-based morphometry of the anterior cingulate cortex in first episode schizophrenia. Hum Brain Mapp 29:478-489. CrossRef Medline

Fox MD, Corbetta M, Snyder AZ, Vincent JL, Raichle ME (2006) Spontaneous neuronal activity distinguishes human dorsal and ventral attention systems. Proc Natl Acad Sci U S A 103:10046-10051. CrossRef Medline

Frodl T, Schüle C, Schmitt G, Born C, Baghai T, Zill P, Bottlender R, Rupprecht R, Bondy B, Reiser M, Möller HJ, Meisenzahl EM (2007) Association of the brain-derived neurotrophic factor Val66Met polymorphism with reduced hippocampal volumes in major depression. Arch Gen Psychiatry 64:410-416. CrossRef Medline

Goghari VM, Rehm K, Carter CS, MacDonald AW 3rd (2007) Regionally specific cortical thinning and gray matter abnormalities in the healthy relatives of schizophrenia patients. Cereb Cortex 17:415-424. CrossRef Medline

Gong Y (1982) Manual of modified Wechsler Adult Intelligence Scale (WAIS-RC) (in Chinese). Changsha, China: Hunan Med College.

Greicius MD, Krasnow B, Reiss AL, Menon V (2003) Functional connectivity in the resting brain: a network analysis of the default mode hypothesis. Proc Natl Acad Sci U S A 100:253-258. CrossRef Medline

Guerini FR, Beghi E, Riboldazzi G, Zangaglia R, Pianezzola C, Bono G, Casali C, Di Lorenzo C, Agliardi C, Nappi G, Clerici M, Martignoni E (2009) BDNF Val66Met polymorphism is associated with cognitive impairment in Italian patients with Parkinson's disease. Eur J Neurol 16:1240-1245. CrossRef Medline

Han X, Jovicich J, Salat D, van der Kouwe A, Quinn B, Czanner S, Busa E, Pacheco J, Albert M, Killiany R, Maguire P, Rosas D, Makris N, Dale A, Dickerson B, Fischl B (2006) Reliability of MRI-derived measurements of human cerebral cortical thickness: the effects of field strength, scanner upgrade and manufacturer. Neuroimage 32:180-194. CrossRef Medline

Hariri AR, Goldberg TE, Mattay VS, Kolachana BS, Callicott JH, Egan MF, Weinberger DR (2003) Brain-derived neurotrophic factor val66met polymorphism affects human memory-related hippocampal activity and predicts memory performance. J Neurosci 23:6690-6694. Medline

Hayasaka S, Phan KL, Liberzon I, Worsley KJ, Nichols TE (2004) Nonstationary cluster-size inference with random field and permutation methods. Neuroimage 22:676-687. CrossRef Medline

Heaton R (1999) Wisconsin Card Sorting Test: Computer Version 3 for Windows. Research Edition. Odessa, FL: Psychological Assessment Resources.

Ho BC, Milev P, O'Leary DS, Librant A, Andreasen NC, Wassink TH (2006) Cognitive and magnetic resonance imaging brain morphometric correlates of brain-derived neurotrophic factor Val66Met gene polymorphism in patients with schizophrenia and healthy volunteers. Arch Gen Psychiatry 63:731-740. CrossRef Medline

Hofer M, Pagliusi SR, Hohn A, Leibrock J, Barde YA (1990) Regional distribution of brain-derived neurotrophic factor mRNA in the adult mouse brain. EMBO J 9:2459-2464. Medline

Huang EJ, Reichardt LF (2001) Neurotrophins: roles in neuronal development and function. Annu Rev Neurosci 24:677-736. CrossRef Medline

Jessen F, Schuhmacher A, von Widdern O, Guttenthaler V, Hofels S, Suliman H, Scheef L, Block W, Urbach H, Maier W, Zobel A (2009) No association of the Val66Met polymorphism of the brain-derived neurotrophic factor with hippocampal volume in major depression. Psychiatr Genet 19:99-101. CrossRef Medline

Jubault T, Gagnon JF, Karama S, Ptito A, Lafontaine AL, Evans AC, Monchi O (2011) Patterns of cortical thickness and surface area in early Parkinson's disease. Neuroimage 55:462-467. CrossRef Medline

Koolschijn PC, van Haren NE, Bakker SC, Hoogendoorn ML, Hulshoff Pol EH, Kahn RS (2010) Effects of brain-derived neurotrophic factor Val66Met polymorphism on hippocampal volume change in schizophrenia. Hippocampus 20:1010-1017. CrossRef Medline

Koscik T, O’Leary D, Moser DJ, Andreasen NC, Nopoulos P (2009) Sex differences in parietal lobe morphology: relationship to mental rotation performance. Brain Cogn 69:451-459. CrossRef Medline

Li Y, Liu B, Hou B, Qin W, Wang D, Yu C, Jiang T (2013) Less efficient information transfer in Cys allele carriers of DISC1: a brain network study based on diffusion MRI. Cereb Cortex 23:1715-1723. CrossRef Medline

Liu B, Li J, Yu C, Li Y, Liu Y, Song M, Fan M, Li K, Jiang T (2010) Haplotypes of catechol-O-methyltransferase modulate intelligence-related brain white matter integrity. Neuroimage 50:243-249. CrossRef Medline

Lotfipour S, Ferguson E, Leonard G, Perron M, Pike B, Richer L, Séguin JR, Toro R, Veillette S, Pausova Z, Paus T (2009) Orbitofrontal cortex and drug use during adolescence: role of prenatal exposure to maternal smoking and BDNF genotype. Arch Gen Psychiatry 66:1244-1252. CrossRef Medline

Lyoo IK, Kim JE, Yoon SJ, Hwang J, Bae S, Kim DJ (2011) The neurobiological role of the dorsolateral prefrontal cortex in recovery from trauma: longitudinal brain imaging study among survivors of the South Korean subway disaster. Arch Gen Psychiatry 68:701-713. CrossRef Medline

Menon V, Uddin LQ (2010) Saliency, switching, attention and control: a network model of insula function. Brain Struct Funct 214:655-667. CrossRef Medline

Owen AM, McMillan KM, Laird AR, Bullmore E (2005) N-back working memory paradigm: a meta-analysis of normative functional neuroimaging studies. Hum Brain Mapp 25:46-59. CrossRef Medline

Panizzon MS, Fennema-Notestine C, Eyler LT, Jernigan TL, Prom-Wormley E, Neale M, Jacobson K, Lyons MJ, Grant MD, Franz CE, Xian H, Tsuang M, Fischl B, Seidman L, Dale A, Kremen WS (2009) Distinct genetic influences on cortical surface area and cortical thickness. Cereb Cortex 19:2728-2735. CrossRef Medline

Patriat R, Molloy EK, Meier TB, Kirk GR, Nair VA, Meyerand ME, Prabhakaran V, Birn RM (2013) The effect of resting condition on resting-state fMRI reliability and consistency: a comparison between resting with eyes open, closed, and fixated. Neuroimage 78:463-473. CrossRef Medline

Pezawas L, Verchinski BA, Mattay VS, Callicott JH, Kolachana BS, Straub RE, Egan MF, Meyer-Lindenberg A, Weinberger DR (2004) The brain-derived neurotrophic factor val66met polymorphism and variation in human cortical morphology. J Neurosci 24:10099-10102. CrossRef Medline

Pontious A, Kowalczyk T, Englund C, Hevner RF (2008) Role of intermediate progenitor cells in cerebral cortex development. Dev Neurosci 30:24-32. CrossRef Medline

Poo MM (2001) Neurotrophins as synaptic modulators. Nat Rev Neurosci 2:24-32. CrossRef Medline

Rakic P (1988) Specification of cerebral cortical areas. Science 241:170-176. CrossRef Medline

Rakic P (2009) Evolution of the neocortex: a perspective from developmental biology. Nat Rev Neurosci 10:724-735. CrossRef Medline

Schofield PR, Williams LM, Paul RH, Gatt JM, Brown K, Luty A, Cooper N, Grieve S, Dobson-Stone C, Morris C, Kuan SA, Gordon E (2009) Disturbances in selective information processing associated with the BDNF Val66Met polymorphism: evidence from cognition, the P300 and frontohippocampal systems. Biol Psychol 80:176-188. CrossRef Medline

Seeley WW, Menon V, Schatzberg AF, Keller J, Glover GH, Kenna H, Reiss AL, Greicius MD (2007) Dissociable intrinsic connectivity networks for salience processing and executive control. J Neurosci 27:2349-2356. CrossRef Medline

Shen YC, Zhang MY, Huang YQ, He YL, Liu ZR, Cheng H, Tsang A, Lee S, Kessler RC (2006) Twelve-month prevalence, severity, and unmet need for treatment of mental disorders in metropolitan China. Psychol Med 36:257-267. CrossRef Medline

Sridharan D, Levitin DJ, Menon V (2008) A critical role for the right frontoinsular cortex in switching between central-executive and default-mode networks. Proc Natl Acad Sci U S A 105:12569-12574. CrossRef Medline

Thomas G, Sinville R, Sutton S, Farquar H, Hammer RP, Soper SA, Cheng YW, Barany F (2004) Capillary and microelectrophoretic separations of ligase detection reaction products produced from low-abundant point mutations in genomic DNA. Electrophoresis 25:1668-1677. CrossRef Medline

Tost H, Alam T, Geramita M, Rebsch C, Kolachana B, Dickinson D, Verchinski BA, Lemaitre H, Barnett AS, Trampush JW, Weinberger DR, Marenco S (2013) Effects of the BDNF Val66Met polymorphism on white matter microstructure in healthy adults. Neuropsychopharmacology 38:525532. CrossRef Medline

Van Dijk KR, Hedden T, Venkataraman A, Evans KC, Lazar SW, Buckner RL (2010) Intrinsic functional connectivity as a tool for human connectomics: theory, properties, and optimization. J Neurophysiol 103:297-321. CrossRef Medline

Van Essen DC (1997) A tension-based theory of morphogenesis and com- 
pact wiring in the central nervous system. Nature 385:313-318. CrossRef Medline

Voineskos AN, Lerch JP, Felsky D, Shaikh S, Rajji TK, Miranda D, Lobaugh NJ, Mulsant BH, Pollock BG, Kennedy JL (2011) The brain-derived neurotrophic factor Val66Met polymorphism and prediction of neural risk for Alzheimer disease. Arch Gen Psychiatry 68:198-206. CrossRef Medline

Weickert CS, Hyde TM, Lipska BK, Herman MM, Weinberger DR, Kleinman JE (2003) Reduced brain-derived neurotrophic factor in prefrontal cortex of patients with schizophrenia. Mol Psychiatry 8:592-610. CrossRef Medline

Yan C, Liu D, He Y, Zou Q, Zhu C, Zuo X, Long X, Zang Y (2009) Sponta- neous brain activity in the default mode network is sensitive to different resting-state conditions with limited cognitive load. PloS One 4:e5743. CrossRef Medline

Yang X, Liu P, Sun J, Wang G, Zeng F, Yuan K, Liu J, Dong M, von Deneen KM, Qin W, Tian J (2012) Impact of brain-derived neurotrophic factor Val66Met polymorphism on cortical thickness and voxel-based morphometry in healthy Chinese young adults. PloS One 7:e37777. CrossRef Medline

Yi P, Chen Z, Zhao Y, Guo J, Fu H, Zhou Y, Yu L, Li L (2009) PCR/LDR/ capillary electrophoresis for detection of single-nucleotide differences between fetal and maternal DNA in maternal plasma. Prenat Diagn 29:217222. CrossRef Medline 